\title{
Environmental, climatic and host population risk factors of human cystic echinococcosis in southwest of Iran
}

\author{
Mohammad Amin Ghatee ${ }^{1,2}$, Koorosh Nikaein $^{3}$, Walter Robert Taylor ${ }^{4,5}$, Mehdi Karamian ${ }^{6}$, Hasan Alidadi ${ }^{3}$, \\ Zahra Kanannejad ${ }^{7}$, Faezeh Sehatpour ${ }^{8}$, Fateme Zarei $^{8}$ and Gholamreza Pouladfar ${ }^{9^{*}}$ (D)
}

\begin{abstract}
Background: Cystic echinococcosis (CE), a worldwide zoonotic disease, is affected by various biological and environmental factors. We investigated dog/livestock populations, climatic and environmental factors influencing the distribution of human CE cases in Fars province, southwest Iran.

Methods: We mapped the addresses of 266 hospitalised CE patients (2004-2014) and studied the effects of different temperature models, mean annual rainfall and humidity, number of frosty days, slope, latitude, land covers, close proximity to nomads travel routes, livestock and dog densities on the occurrence of CE using geographical information systems approach. Data were analyzed by logistic regression.

Results: In the multivariate model predicting CE, living in an urban setting and densities of cattle and dogs were the most important CE predictors, sequentially. Dry (rained) farm, density of camel and sheep, close proximity to nomads travel routes, humidity, and slope also were considered as the determinants of CE distribution, when analyzed independently. Slope had a negative correlation with CE while temperature, frost days and latitude were not associated with CE.

Conclusions: In our study, an urban setting was the most important risk factor and likely due to a combination of the high density of key life cycle hosts, dogs and livestock, a large human susceptible population and the high number of abattoirs. Farmland and humidity were highly suggestive risk factors and these conditions support the increased survival of Echinococcus granulosus eggs in the soil. These findings support the development of strategies for control of disease. More research is needed test optimal interventions.
\end{abstract}

Keywords: Cystic echinococcosis, GIS, Climate, Livestock, Environment

\section{Background}

The larval stage of the cestode parasite Echinococcus granulosus sensu lato (E. granulosus s. 1.) causes cystic echinococcosis (CE) also known as cystic hydatid disease, a chronic parasitic zoonosis of humans and

\footnotetext{
* Correspondence: Pouladfar_ghr@hotmail.com

${ }^{9}$ Professor Alborzi Clinical Microbiology Research Center, Department of Paediatrics, Nemazee Teaching Hospital, School of Medicine, Shiraz University of Medical Sciences, Shiraz, Iran

Full list of author information is available at the end of the article
}

domestic and wild mammals. CE is a disease of poverty and usually occurs in herding communities [1, 2]. Canids are the definitive hosts of E. granulosus and herbivores (e.g. sheep, goats, cattle) are the main intermediate hosts. Humans acquire $\mathrm{CE}$ by accidentally ingesting $E$. granulosus eggs in food, water, or contaminated soil [3]. After ingestion, Echinococcus eggs hatch and embryos are released in the small intestine. Primary larval penetration through the mucosa leads to blood borne distribution to various body organs [4] with most cysts

C C The Author(s). 2020 Open Access This article is licensed under a Creative Commons Attribution 4.0 International License, which permits use, sharing, adaptation, distribution and reproduction in any medium or format, as long as you give appropriate credit to the original author(s) and the source, provide a link to the Creative Commons licence, and indicate if changes were made. The images or other third party material in this article are included in the article's Creative Commons licence, unless indicated otherwise in a credit line to the material. If material is not included in the article's Creative Commons licence and your intended use is not permitted by statutory regulation or exceeds the permitted use, you will need to obtain permission directly from the copyright holder. To view a copy of this licence, visit http://creativecommons.org/licenses/by/4.0/. The Creative Commons Public Domain Dedication waiver (http://creativecommons.org/publicdomain/zero/1.0/) applies to the data made available in this article, unless otherwise stated in a credit line to the data. 
developing in the liver (70\%) and lungs (20\%) due to capillary filtration [5]. Other affected organs include the spleen, heart, brain, kidney, peritoneum and bone [6]. The clinical manifestations of $\mathrm{CE}$ are broad, ranging from clinically silent cysts [7] to anaphylactic shock caused by the rupture of cysts and spillage of their contents [2].

$\mathrm{CE}$ is a worldwide public health problem, with highly endemic areas in some regions of South America, North Africa, China, and the Middle East, including Iran. Conventional livestock husbandry and widespread close contact between people and animals are key factors in the hyper endemicity of $\mathrm{CE}$ in Iran, where $1 \%$ of all surgeries are linked to CE [8-10].

Within the E. granulosus s. L. complex, there are 10 genotypes (G1-G10) and four species. The identification of species and strains is important for CE control programs, for disease prevention and epidemiological tracking of cases [11]. In Iran, G1, G2, G3 and G6 genotypes have been reported from humans and livestock including sheep, goats, camels and cattle, while the G7 genotype is isolated only from sheep and goats [12-15]; G1 is the most frequent followed by G6 and in Fars province, southwestern Iran, only G1 and G6 genotypes have been found in the hosts $[12,16]$.

Risk factors for $\mathrm{CE}$ in endemic regions include the presence of free roaming dogs, being a dog owner, slaughtering livestock at home or in inadequately supervised slaughterhouses [17]. Moreover, the CE cycle is extensively dependent to environmental and climatic factors due to their effects on the survival of eggs and on the living conditions of humans and livestock. E. granulosus eggs passed in dog faeces may survive 3 weeks at $30{ }^{\circ} \mathrm{C}, 4.5$ weeks at $10-21{ }^{\circ} \mathrm{C}$, and 32 weeks at $6{ }^{\circ} \mathrm{C}$ in water and damp sand and for several months in green pastures and gardens [18]. Also, livestock and stray dog's life as the main intermediate and final hosts are extensively affected by environmental and climatic conditions.

Geographical information systems (GIS) are computerbased approaches for integrating and analyzing geo-spatial data. They are valuable tools for studying the effects of environmental and climatic factors on disease occurrence [19], predicting disease trends and distribution, and modelling the control of diseases over time [20,21]. GIS have been used recently to study different parasitic diseases such as leishmaniasis and malaria in Iran $[22,23]$.

GIS-based studies on human CE are few in different countries where some geo-climatic factors have not been even approached so far. Fars is the largest province in southwest Iran and one of the highest endemic areas of $C E$ with human infection rate up to 13.7\% [24], but GIS analyses have not been used to study $\mathrm{CE}$ distribution and role of the main geoclimatic factors on $\mathrm{CE}$ in this region. Herein, we comprehensively report on the host, environmental and climatic factors affecting human CE in Fars.

\section{Methods \\ Study area}

Fars Province lies in southwest Iran, between longitude $27^{\circ} 31^{\prime} \mathrm{N}$ to $31^{\circ} 42^{\prime} \mathrm{N}$ and latitude $50^{\circ} 37^{\prime} \mathrm{E}$ to $55^{\circ} 38^{\prime} \mathrm{E}$, and covers an area of about $122,608 \mathrm{~km}^{2}$ (Fig. 1). The total population of Fars is about 4.6 million with a male to female ratio of 1: 1.03. Administratively, it is divided into 24 counties and Shiraz is the provincial capital. The region encompasses a variety of landscapes from dense forests to bare plains and elevations of 115 to $3115 \mathrm{~m}$ above sea level; the Zagros mountain range stretches from the northwest to the southeast and covers $70 \%$ of Fars. The population consists of urban, suburban and rural dwellers and there is a substantial nomadic population; the latter come from different clans who spend much of their lives herding their livestock and dogs between their winter (Qishlag) and summer quarters (Yailaq) along well established routes.

\section{Data collection}

From 2004 to 2014, we obtained the addresses of 266 patients who were treated for confirmed CE at hospitals of Fars province. All data were retrieved from patient's records and gathered in Professor Alborzi Clinical Microbiology Research Center in Namazi hospital in Shiraz.

\section{Geospatial data}

The CE patients' residences were recorded on the point shape file map of Fars province, according to the latitudes and longitudes of the villages and cities from which the patients were drawn. The digital elevation model (DEM) raster layer and the province and land cover vector layers were acquired from the Department of Natural Resources in Fars province. The slope raster map was drawn through spatial analyst tool, based on DEM, by computing the maximal rate of variation in value between each cell and its adjacent cells and the land cover layer shows spatial data on the different physical characteristics of the surface of the province.

For the period 2004 to 2014, temperatures, humidity and evaporation data and the frequencies of rainy and frosty days, from 18 synoptic meteorological stations, and rainfall data from 86 rain-gauge stations were acquired from the Fars Province Weather Bureau. From these data, the mean annual temperature (MAT), maximum mean annual temperature (maximum MAT), minimum mean annual temperature (minimum MAT), mean annual humidity (MAH), mean annual rainfall (MAR), mean annual evaporation (MAE) and mean rainy and frosty days were calculated. After testing 


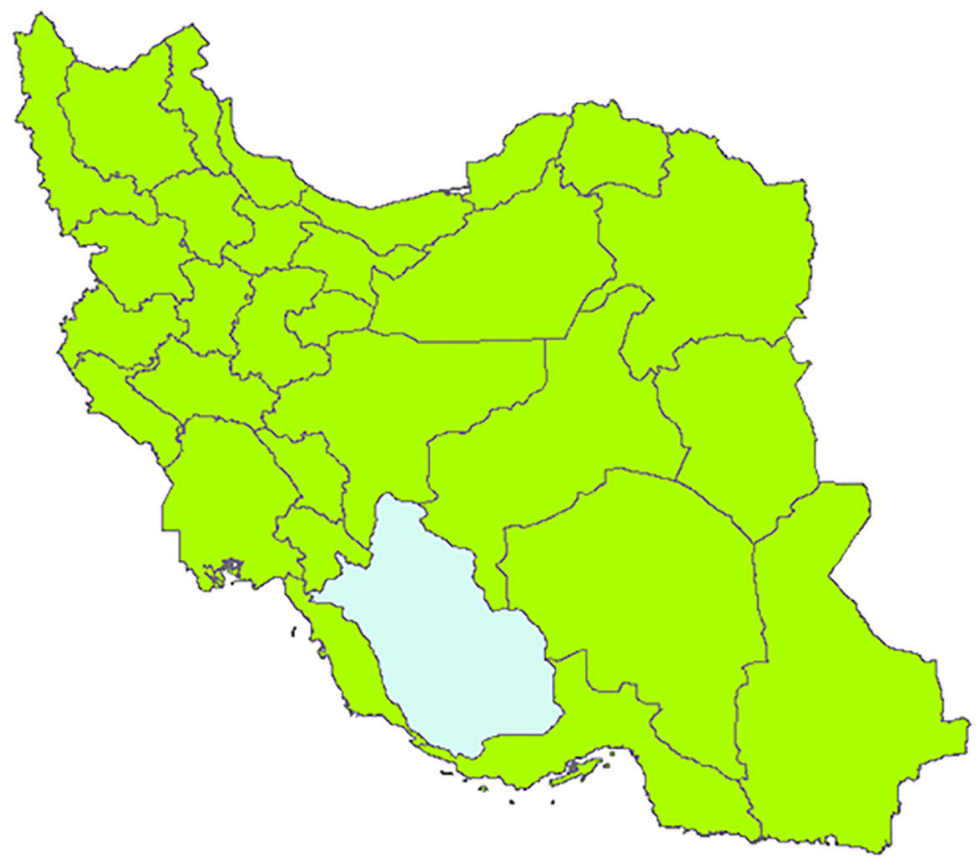

$375 \quad 187.5 \quad 0$

375 kilometers

Fig. 1 Map of Iran showing Fars province in the southwest. Note: Map was created with ArcMap from ArcGIS 10.1

various interpolation methods, the annual iso-hydral, iso-humid and frost days raster layers were generated using the Kriging interpolation method and iso-thermal, iso-evaporation and rainy days raster layers using the tension based Spline interpolation model with a resolution grid of $2 \times 2 \mathrm{~km}$.

\section{Nomad travel routes risk maps}

The vector layer of nomads' travel routes (NTR) was obtained from the Nomads Affairs Administration of Fars province. Two risk maps were developed by unifying the buffers $(2$ and $5 \mathrm{~km})$ that made around the routes along which the nomads migrate between Yailaq and Qishlag to investigate the association between nomad population and CE occurrence.

\section{Livestock and dog densities}

The livestock and dog data, including geographical coordinates of livestock sheds and the number of sheep, goats, cows, camels and dogs in each shed, were obtained from the Fars province Veterinary Bureau to generate a livestock shed point shapefile layer and animal density raster layers using the Kernel (method) density method.

\section{Geospatial analysis}

ArcGIS version 10.1 (http://www.esri.com/arcgis) was used to analyze geospatial and climatic data. The provincial villages and cities point shape file layer was extracted with the raster layers. The identity tool was used to compute the geometric intersection of the layer 
obtained from the extraction of all raster layers with NTR hazard (polyline) and land cover (polygonal) vector layers to develop the final layer in which each point represented properties of all the overlapped identity features from the above-mentioned raster and vector layers. The attribute of this layer was converted to an excel format for statistical analysis. All maps were provided by Ghatee et al. by using ArcMap from ArcGIS 10.1.

\section{Statistical analysis}

After the spatial description of CE patients in Fars province, the association between disease and possible the risk factors (i.e. human and animal populations, climate, and environment) was investigated. Accordingly, residential points data including CE reported and nonreported villages and cities were extracted from final province villages/cities point layer and analyzed using univariate and multivariate Enter logistic regression models. The analyses were performed using SPSS version 21 .

\section{Results}

Geo-climatic distribution of infected points

A total of $266 \mathrm{CE}$ patients were identified from hospital records who lived in 134 points in the province, representing $1.6 \%$ of the 8182 villages and cities in Fars. Villages/cities with report of cases of CE were distributed in different parts of province but three clusters were evident in central, western and southeastern areas of Fars with most cases coming from the central region. One hundred thirty nine and 127 of patients were from cities and rural points, respectively.

Similarly, villages/cities with CE cases reported were distributed in regions with different climatic and environmental conditions. The elevation and slope varied from 279 to $2365 \mathrm{~m}$ and $0-43$ degrees, respectively (Fig. 2). MAT, minimum and maximum MAT ranged $12.8-25.6^{\circ} \mathrm{C}, 5.1-17.1^{\circ} \mathrm{C}$ and $18.1-34.1^{\circ} \mathrm{C}$, respectively (Fig. 3). MAR ranged from 115 to $540 \mathrm{~mm}$, minimum and maximum air humidity were 33 and $67 \%$, respectively, and evaporation levels were between 1889 and $3385 \mathrm{~mm}$ among villages/cities with CE cases reported

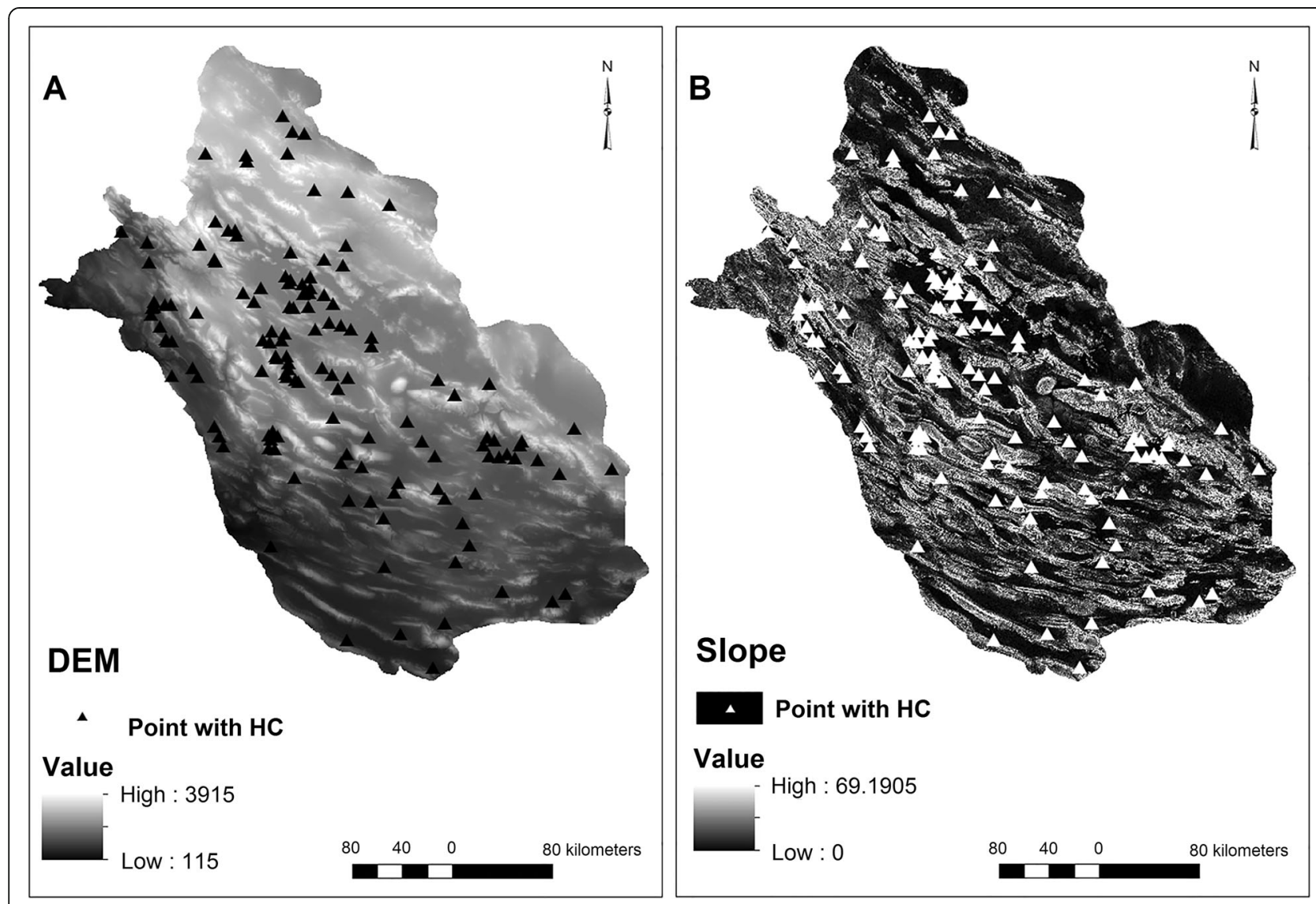

Fig. 2 Digital elevation model (a) and Slope (b) maps. Infected points were shown by triangle symbol. No cases of hydatid cyst were reported on the slopes higher than 43 degrees. The digital elevation model (DEM) raster layer was acquired from the Department of Natural Resources in Fars province, Iran. Slope raster layer was generated based on the DEM layer. Note: Maps were created with ArcMap from ArcGIS 10.1 by our team 

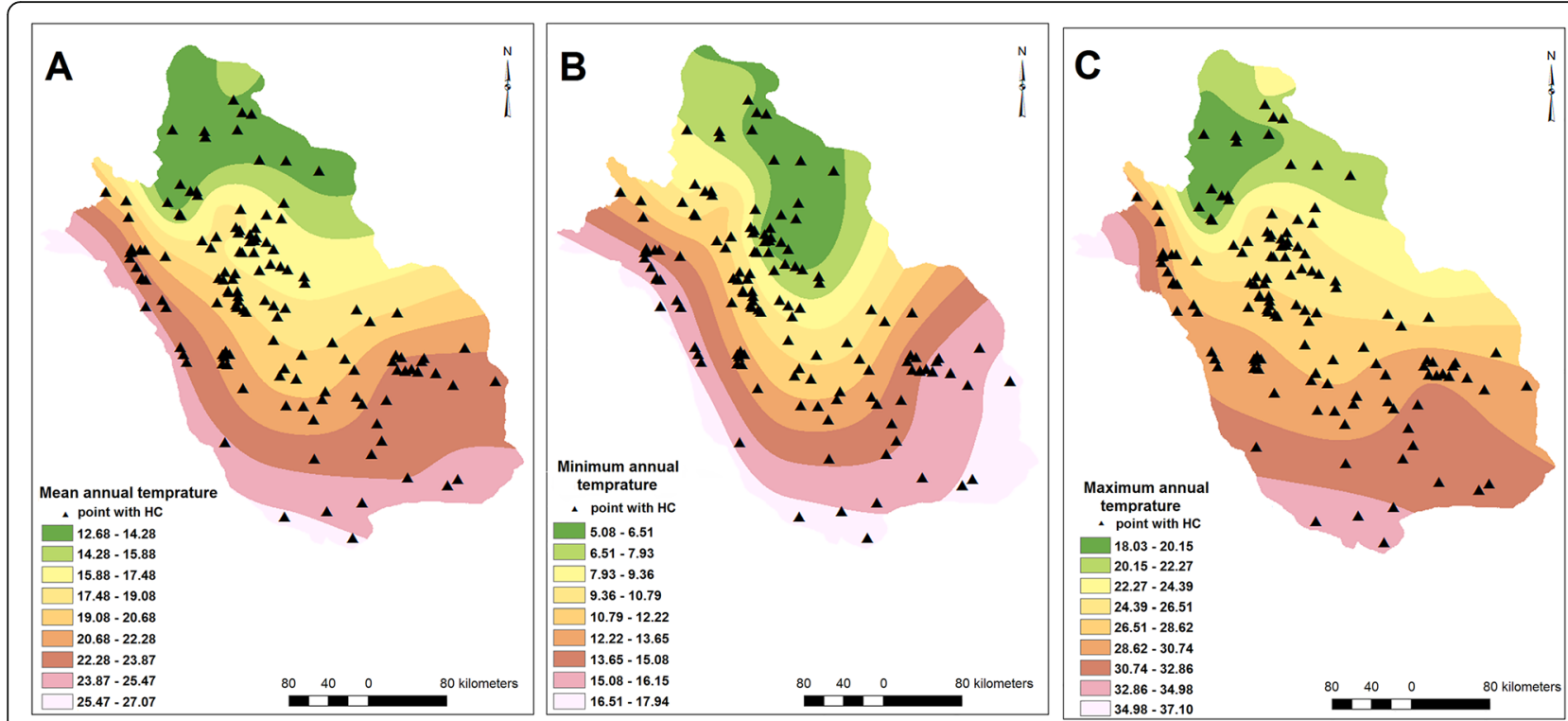

Fig. 3 Isothermal models rasters; Mean annual temperature (a), Minimum mean annual temperature (b), and Maximum mean annual temperature (c). Infection points were distributed in different ranges of temperature and no association was detected between different models of temperature and hydatid cyst distribution in Fars province. Note: Maps were created with ArcMap from ArcGIS 10.1. The mentioned layers and maps were generated by our team based on the meteorological data

(Fig. 4). The number of rainy days and frosty days ranged $22-51$ and 7-86 days, respectively for these points (Fig. 5). The majority of infected points were found different types of terrain and the highest ratio of infected point frequency was found in urban areas followed by dry and irrigated farmlands (Table 1, Fig. 6).

\section{Univariate logistic regression}

\section{Environmental and climatic factors}

The logistic regression for single variable model showed irrigated, dry farms and urban land covers, slope and $\mathrm{MAH}$ effect on CE occurrence in southwest Iran. Among them, land covers showed the highest effect on

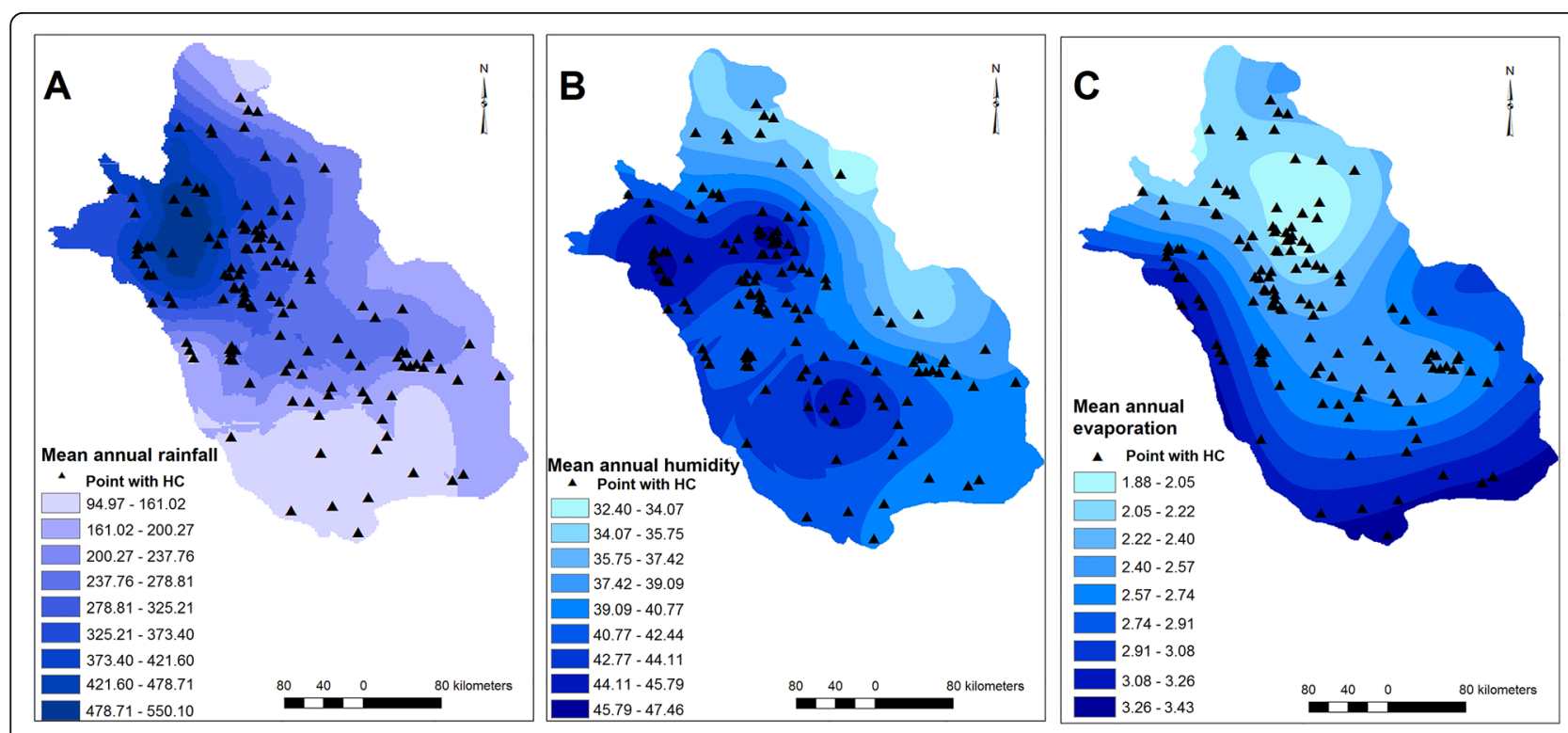

Fig. 4 Rainfall (MAR) (a), Humidity (MAH) (b) and evaporation (MAE) (c) ratser models. Note: Maps were created with ArcMap from ArcGIS 10.1 and by our team based on the meteorological data 


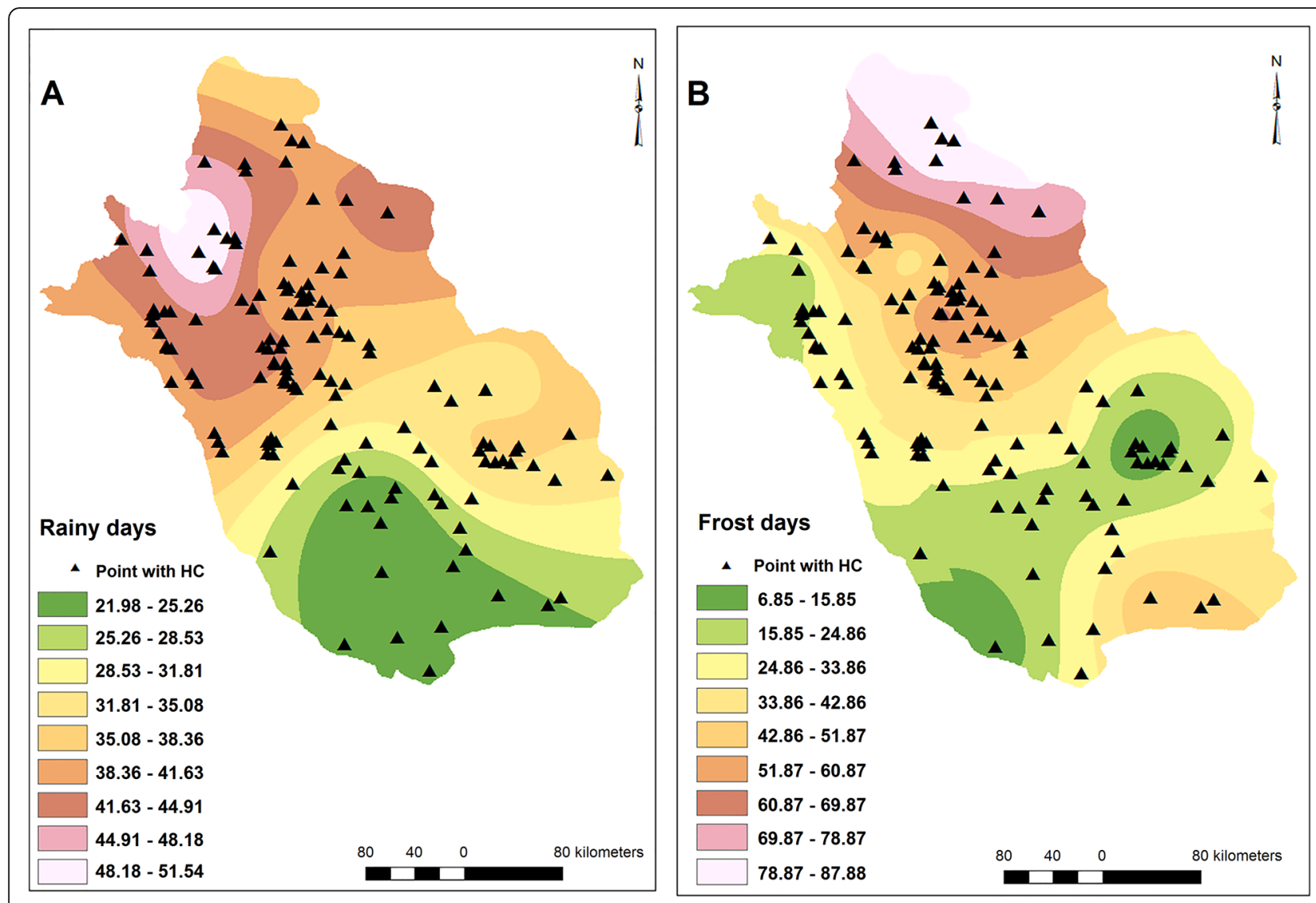

Fig. 5 The raster maps of the number of rainy days (a) and frosty days (b) and the distribution of infection points. Hydatid disease was not associated with these factors in Fars province. Note: Maps were created with ArcMap from ArcGIS 10.1 and by our team based on the meteorological data

the occurrence of CE; Urban ( $p$ value $<0.001, \mathrm{OR}=$ $97.01)$, dry farm ( $\mathrm{p}$ value $=0.038, \mathrm{OR}=10.23$ ) and irrigated farm $(p$ value $=0.022, \mathrm{OR}=10.03)$. Ratio of villages $/$ cities with $C E$ cases reported to all points was higher than 1 in the above-mentioned land covers (Table 2). Increasing slope protected against $C E$ ( $\mathrm{p}$ value $=0.002, \mathrm{OR}=0.935$ ) while humidity showed positive correlations with $\mathrm{CE}(\mathrm{p}$ value $<0.001$, $\mathrm{OR}=1.13$ ). Increase of one unit of each aforesaid determinant increased and decreased the possibility of CE occurrence by 13 and $6.5 \%$, respectively (Fig. 2, Fig. 4). Other geo-climatic factors including MAT, maximum MAT, minimum MAT, MAR, elevation, and the number of frost and rainy days had no significant effect on the occurrence of CE in our study (Table 2).

\section{Effect of close proximity to NTR}

Close proximity to NTR also affects on the occurrence of CE in the Fars province (Table 2). Presence of village/

Table 1 The distribution of CE infection points and all points and their ratios in various land covers of Fars province

\begin{tabular}{llll}
\hline Land cover & Infected points per feature (\%) & All points per feature (\%) & Ratio \\
\hline Urban & 14.9 & 1.3 & 11.46 \\
Condensed and Semi-condensed forest & 0.7 & 5.2 & 0.13 \\
Sparse forest & 2.2 & 10.2 & 0.22 \\
Condensed and Semi-condensed rangeland & 4.5 & 9.3 & 0.48 \\
Thin rangeland & 12.7 & 27 & 0.47 \\
Dry (rainfed) farm & 3 & 2.1 & 1.43 \\
Irrigated farm & 59 & 41.6 & 1.42 \\
Salt land, salinity and water area & 3 & 3.4 & 0.88 \\
Total & 100 & 100 & \\
\hline
\end{tabular}




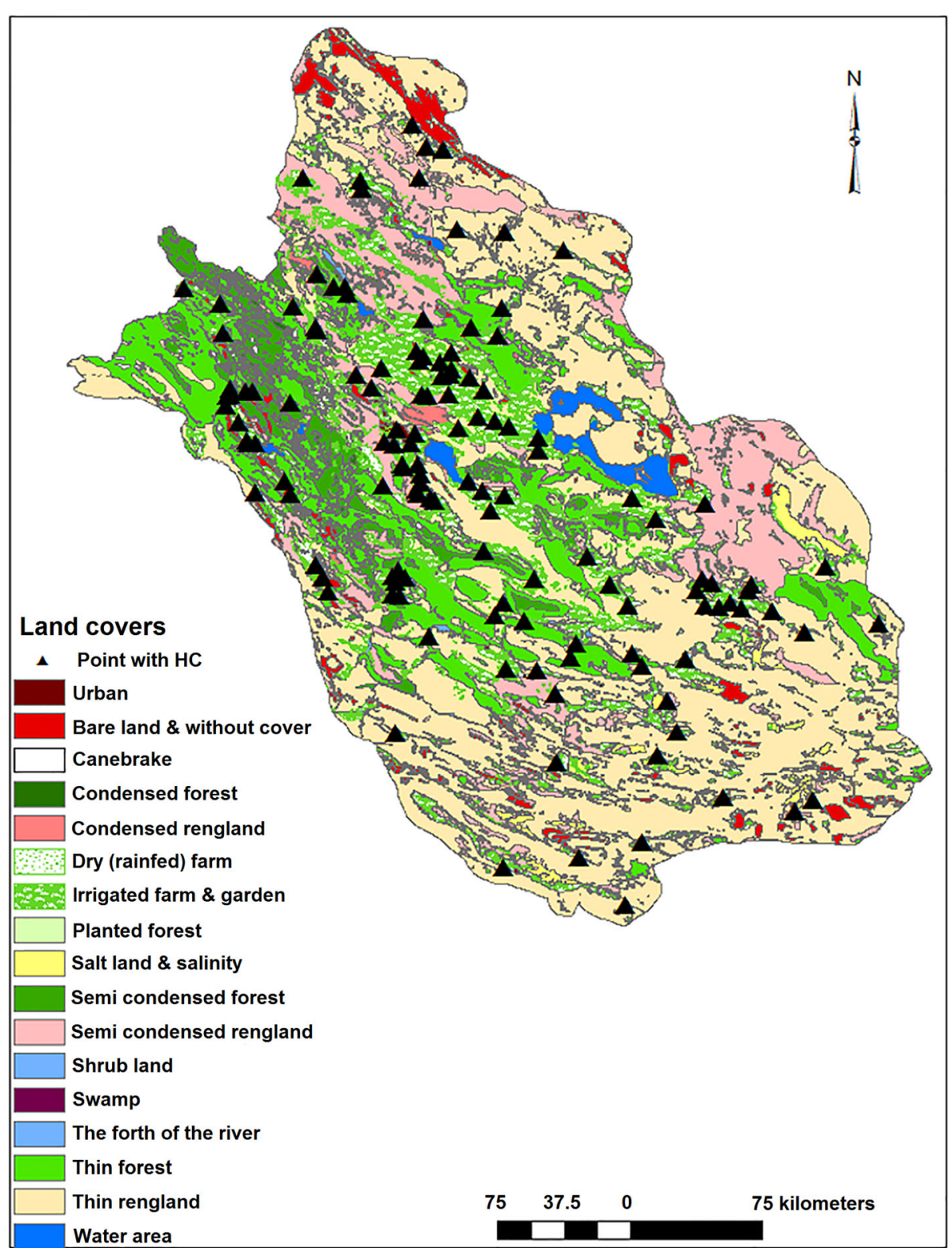

Fig. 6 Land cover vector map of Fars province. A notable number of infection points were distributed in farmlands and urban areas. Urban areas are marked by triangles. Note: Map was created with ArcMap from ArcGIS 10.1. The land cover vector layers were acquired from the Department of Natural Resources in Fars province, Iran

city points in $2 \mathrm{~km}$ and $5 \mathrm{~km}$ buffers increased the possibility of CE occurrence by $208 \%$ ( $p$ value $<0.001$, OR $=$ 2.087 ) and $219 \%(p$ value $<0.001$, $\mathrm{OR}=2.191)$, respectively. From 134 points with report of CE, 66 and 96 points were distributed in $2 \mathrm{~km}$ and $5 \mathrm{~km}$ buffers around NTR, respectively (Table 2, Fig. 7).

\section{Livestock and dog densities}

The density of sheep/goat ( $p$ value $<0.001, \mathrm{OR}=1.006$ ), cattle $(p$ value $<0.001, \mathrm{OR}=1.038), \operatorname{dog}(p$ value $<0.001$, $\mathrm{OR}=3.121)$ and camel $(p$ value $=0.029, \mathrm{OR}=4.046)$ in $\mathrm{km}^{2}$ significantly influenced CE distribution and increased the possibility of disease occurrence (Table 2). Density of camel was the most effective determinant among the animals on the CE occurrence (Table 2, Fig. 8).

\section{Multivariate logistic regression model}

Of the 16 tested variables (Table 3), only an urban setting ( $p$ value $<0.001, \mathrm{OR}=67.646)$ and density of dogs $(p$ value $=$ $0.037, \mathrm{OR}=1.944)$ and cattle $(p$ value $=0.007, \mathrm{OR}=1.203)$ were significant explanatory variables whilst irrigated farms were borderline significant and there were trends for dry 
Table 2 Results of Univariate logistic regression model for evaluation of effect of geo-climatic factors, close proximity to NTR and animal densities on CE in Fars province, southwest Iran

\begin{tabular}{|c|c|c|c|}
\hline Variable & $P$-value & OR & $\mathrm{Cl}$ \\
\hline \multicolumn{4}{|l|}{ Land cover } \\
\hline Condensed and semi condensed forest & $<0.001^{\mathrm{a}}$ & & \\
\hline Sparse forest & 0.717 & 1.520 & $0.158-14.655$ \\
\hline Condensed and semi-condensed rangeland & 0.263 & 3.358 & $0.403-27.987$ \\
\hline Thin rangeland & 0.250 & 3.270 & $0.434-24.636$ \\
\hline Dry (rainfed) farm & 0.038 & 10.230 & $1.135-92.207$ \\
\hline Irrigated farm & 0.022 & 10.039 & $1.393-72.339$ \\
\hline urban & $<0.001$ & 97.011 & $12.849-732.461$ \\
\hline Salt land, salinity and water area & 0.103 & 6.206 & $0.690-55.818$ \\
\hline MAT & 0.8 & 1.006 & $0.959-1.056$ \\
\hline MinMAT & 0.398 & 0.980 & $0.934-1.027$ \\
\hline MaxMAT & 0.695 & 1.009 & $0.966-1.054$ \\
\hline MAR & 0.157 & 1.001 & $1.000-1.003$ \\
\hline MAH & $<0.001$ & 1.136 & $1.068-1.209$ \\
\hline MAE & 0.283 & 1.000 & $0.999-1.000$ \\
\hline Mean rainy day & 0.512 & 1.008 & $0.984-1.032$ \\
\hline Elevation & 0.058 & 1.000 & $0.999-1.000$ \\
\hline slope & 0.002 & 0.935 & $0.897-0.975$ \\
\hline Frost day & 0.645 & 1.002 & $0.993-1.011$ \\
\hline $2 \mathrm{~km}$ buffer around NTR & $<0.001$ & 2.087 & $1.482-2.937$ \\
\hline $5 \mathrm{~km}$ buffer around NTR & $<0.001$ & 2.191 & $1.501-3.198$ \\
\hline Sheep density & $<0.001$ & 1.006 & $1.003-1.009$ \\
\hline Cattle density & $<0.001$ & 1.038 & $1.029-1.047$ \\
\hline Camel density & 0.029 & 4.046 & $1.150-14.241$ \\
\hline Dog density & $<0.001$ & 3.121 & $2.104-4.630$ \\
\hline
\end{tabular}

${ }^{a}$ Condensed and semi-condensed forest was fitted as reference group for landcovers. Cl Confidence interval, OR Odd's ratio, MAT Mean annual temperature, MinMAT Minimum mean annual temperature, MaxMAT Maximum mean annual temperature, MAR Mean annual rainfall, MAH Mean annual humidity, MAE Mean annual evaporation, NTR Nomad travel route

farmlands and humidity. Urban land cover was the most important predictive determinant in this model.

\section{Discussion}

We have shown that the occurrence of $\mathrm{CE}$ in Fars province, southwestern Iran, was affected mainly by an urban setting and the densities of cattle and dogs. Our results also suggest that different types of farmland, humidity, density of camel and sheep, proximity to nomadic travel routes, and slope also affected the distribution of $\mathrm{CE}$ when evaluated independently from other factors.

An urban setting was the most important factor in the distribution of CE and this is related to the size of urban populations, the industrial herding of large flocks of sheep and goat and, the presence of a large number of stray dogs in the suburb of urban areas. Moreover, populations living in suburbs of cities and metropolitans mostly have lower socioeconomic conditions, and usually breed livestock and shepherd dogs in the suburbs and periurban areas [25], where livestock is slaughtered in abattoirs, butchers' shops and peoples' homes. It is well established that dogs may become infected by eating the offal of slaughtered livestock in nearby local butcher shops and abattoirs or from houses in which sheep are killed for household consumption [26, 27]. Torgerson et al. (2003) showed that a higher prevalence of infection was found in dogs which are closely associated with livestock in comparison to dogs kept as house pets [28]. This may have been important in our study but we did not examine this. Consistent with the distribution of zoonotic related leishmaniasis in southwest Iran, where dogs are the most important reservoirs, urban areas are also an important determinant of this disease [29].

Densities of cattle and dogs were the next factors explaining the distribution of human CE. Canids especially dogs, as the definitive hosts of E. granulosus, are 

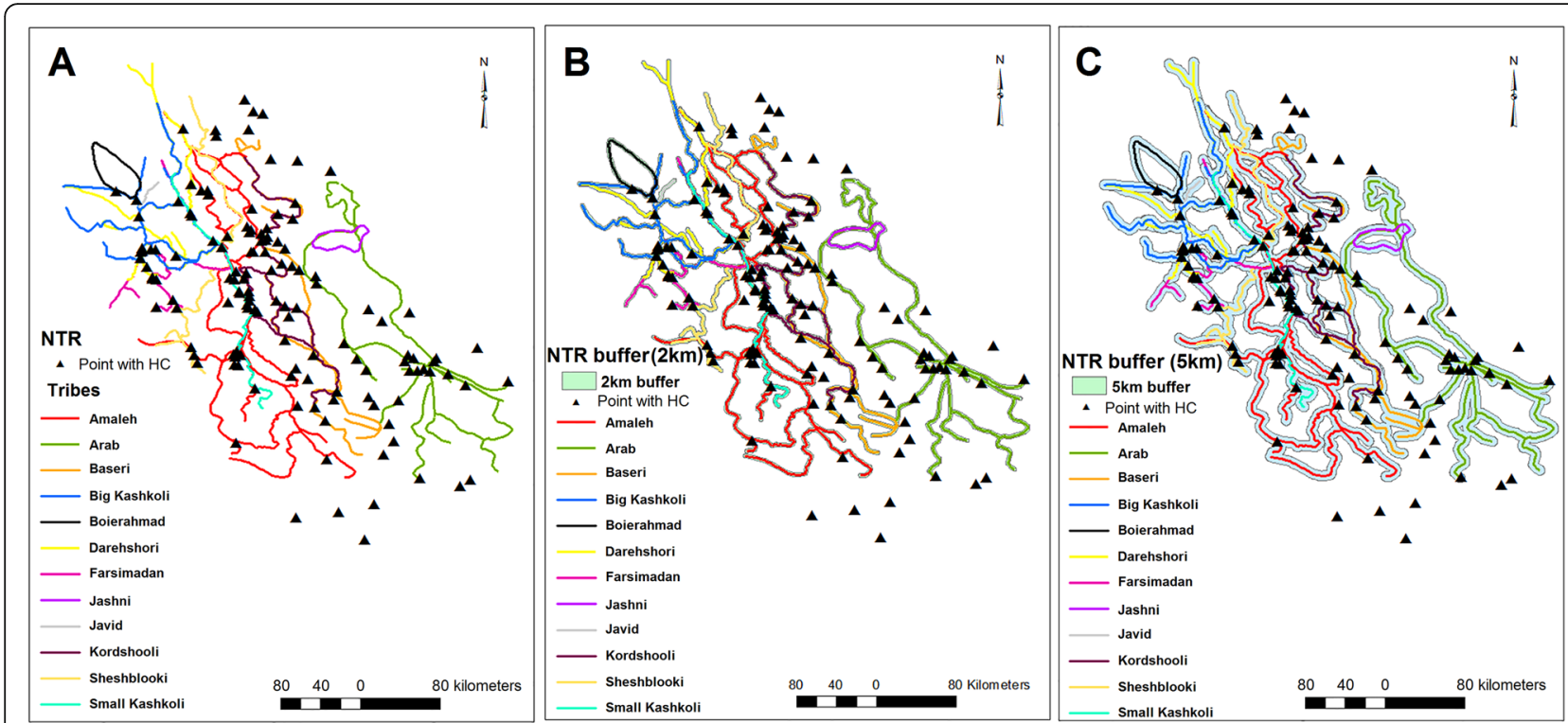

Fig. 7 Maps of nomad travel routes (a) and $2 \mathrm{~km}$ (b) and $5 \mathrm{~km}$ (c) buffers around nomad travel routes. Most of the infection points are located close to these routes. Note: Maps were created with ArcMap from ArcGIS 10.1. The vector layer of nomads' travel routes (NTR) was obtained from the Nomads Affairs Administration of Fars province, Iran

necessary for the continued transmission of CE. Dogs become infected principally by consuming infected offal of slaughtered ruminants left lying around in insanitary and substandard abattoirs. In some provinces of Iran, it is stray dogs that have the highest rate of Echinococcus infection (19.1\%) among the canids [30] and studies also reported high infection rates in shepherd dogs, up to $63.3 \%$ [27].

In our study, cattle were the most important livestock affected the occurrence of human CE in Fars province. Although the number of sheep and goats is higher than cattle in the studied areas, the CE prevalence rates in Fars are highest in cattle (11\%), sheep (just under 5\%) and goats (4.5\%) [31]. Also, another study in northern Iran (Mazandaran province), showed that $40.1 \%$ of cattle and $37.8 \%$ of goats were infected by CE [32].

The importance of cattle may be related to the timing of their slaughter. They are slaughtered in older age than sheep and goat; therefore, potential E. granulosus egg exposure is longer in cattle [3]. The higher prevalence of $\mathrm{CE}$ in older cattle was reported in some studies which is also due to more exposure time with pastures contaminated with egg [33-35].

Farming was the other important factor that we identified due to the herding of livestock, with sheepdogs, on farmland. High soil moisture, especially in irrigated farms, supports the survival of E. granulosus eggs [36], and increases the probability of disease transmission to intermediate hosts. In China, Yang et al. showed that an increase in farming following deforestation was associated with an increased risk of $\mathrm{CE}$ in humans and intermediate herbivores [37]. In Italy, the green fodder around cattle farms was assumed as the main cause of infection of cattle with Echinococcus eggs [7]. Limited knowledge of hydatid disease among farmers working in these areas also plays a considerable role in the occurrence of CE in farm regions [38, 39].

In our univariate analysis, camel density was an important risk factor that was not significant in the multivariate model. However, other data from Iran support the importance of camels as intermediate hosts. Some $35 \%$ of slaughtered camels from different regions of Iran were infected with hydatid cysts [40], in southwest region including Fars province, CE prevalence rates was (70\%) higher than central (64\%), South (42\%) and northeast (11\%) regions, [41-43] indicating the high potential of camel in the transmission of E. granulosus in Fars province.

Close proximity to NTR was also an effective factor in the univariate model but not in the multivariate model. Nevertheless, the herding life style of nomadic populations results in close contact with sheep, goats, and dogs and ample opportunity to be infected by CE. Furthermore, on their twice annual long journeys of hundreds of kilometers, nomads pass through known areas endemic for CE and have contact with stray dogs and wild canids, exposing them and their dogs to different $\mathrm{CE}$ strains; moreover, serological studies have shown high seropositivity for $\mathrm{CE}$ in nomadic populations. In recent times, many nomadic families have changed their lifestyles and have opted to settle in villages and cities near their NTRs where their presence may enhance CE 

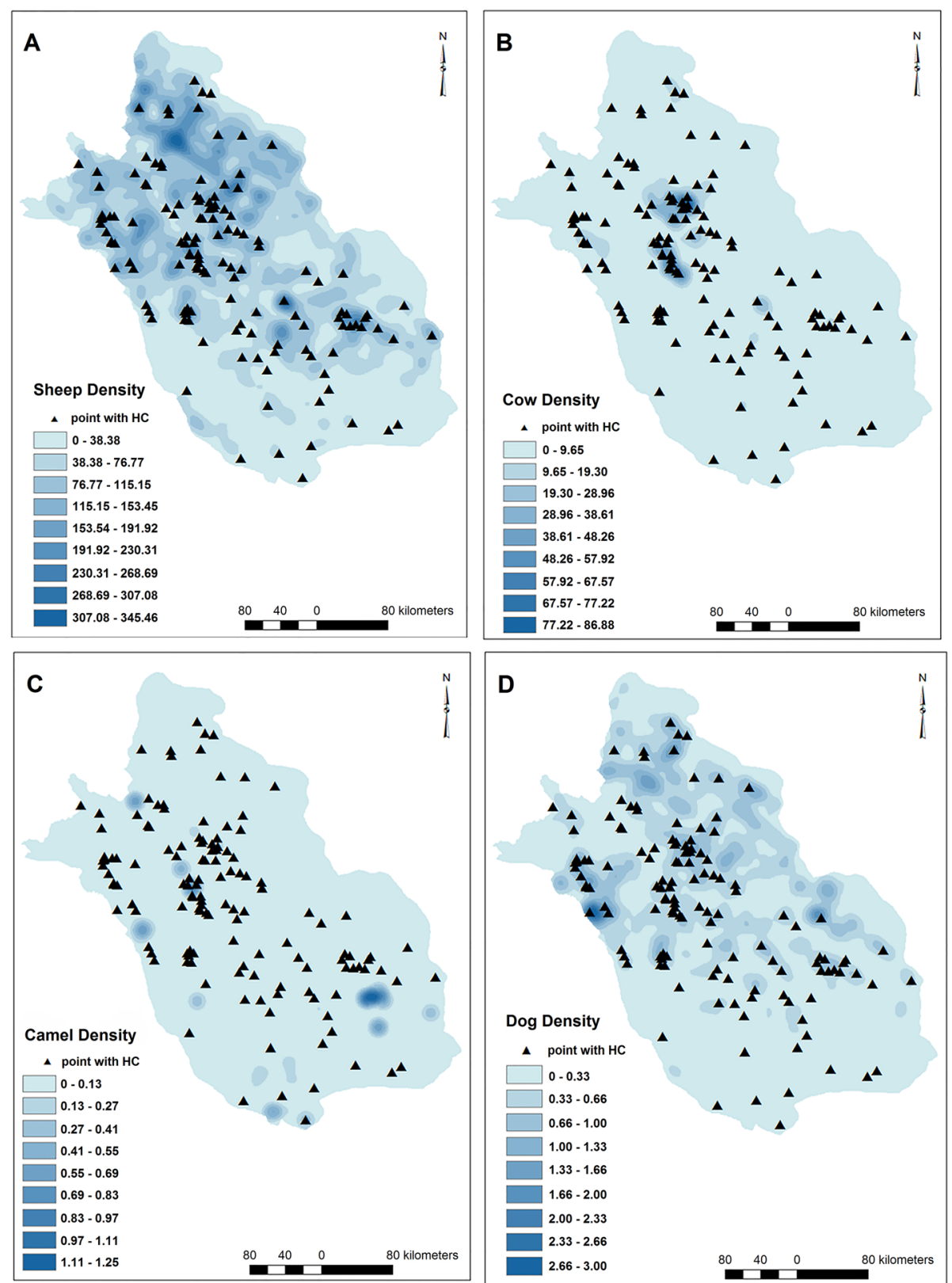

Fig. 8 The raster maps of the densities of sheep or goats $(\mathbf{a})$, cattle $(\mathbf{b})$, camels $(\mathbf{c})$ and dogs $(\mathbf{d})$. Note: Maps were created with ArcMap from ArcGIS 10.1 and by our team based on the livestock data

transmission [29]. In Iran, Rafiei et al. reported a 14\% seropositivity rate in nomads compared to $4.3 \%$ in rural inhabitants $[44,45]$.

Humidity was a significant factor in the univariate model and showed a strong trend for CE occurrence in the multivariate model and results in increased soil moisture, especially in winter, and this greatly increases the chances of egg survival and therefore, transmission of infection to intermediate hosts and human [46]. Wang et al. showed that the concentration of E. granulosus eggs was higher in the seasons with more moisture like winter [47], and Laws et al. have confirmed the greater longevity of $E$. granulosus eggs in humid conditions with survival rates of 50, 20 and $5 \%$ in 80,60 and $25 \%$ relative humidity, respectively [48].

Slope was revealed as the factor with limiting effect with the univariate model on CE occurrence in southwest Iran, where more CE reported villages/cities were found in lower slope. Generally, rainwater carries eggs from high lands to low altitudes and lower slope regions. Also, Guislain et al. revealed eggs which were washed by rain can survive more than 
Table 3 Results of enter multivariate logistic regression model analysis

\begin{tabular}{|c|c|c|c|}
\hline Variable & $P$-value & OR & $\mathrm{Cl}$ \\
\hline \multicolumn{4}{|l|}{ Land cover } \\
\hline Condensed and Semi condensed forest & $<0.001$ & & \\
\hline Mean humidity & 0.072 & 1.073 & $0.994-1.158$ \\
\hline Slope & 0.881 & 1.003 & $0.964-1.043$ \\
\hline Sparse forest & 0.789 & 1.363 & $0.140-13.264$ \\
\hline Condensed and Semi-condensed rangeland & 0.276 & 3.298 & $0.385-28.216$ \\
\hline Thin rangeland & 0.213 & 3.368 & $0.474-28.631$ \\
\hline Dry (rainfed) farm & 0.081 & 7.468 & $0.782-71.332$ \\
\hline Irrigated farm & 0.050 & 7.460 & $0.969-57.431$ \\
\hline Urban & $<0.001$ & 67.646 & $8.371-546.632$ \\
\hline Salt land, salinity and water area & 0.144 & 5.205 & $0.570-47.571$ \\
\hline $2 \mathrm{~km}$ buffer around NTR & 0.156 & 1.384 & $0.883-2.168$ \\
\hline $5 \mathrm{~km}$ buffer around NTR & 0.981 & 1.006 & $0.595-1.701$ \\
\hline Livestock density & 0.558 & 0.440 & $0.028-6.856$ \\
\hline Sheep density & 0.906 & 1.000 & $0.996-1.004$ \\
\hline Cattle density & 0.007 & 1.203 & $1.006-1.041$ \\
\hline Camel density & 0.801 & 1.251 & $0.220-7.103$ \\
\hline Dog density & 0.037 & 1.944 & $1.040-3.636$ \\
\hline
\end{tabular}

dry eggs $[49,50]$. On the other hand, historically humans have been forming villages near the rivers, in low altitude regions which are often in low slope. The restricting effect of increase of slope on the occurrence of other parasitic diseases was reported in southwest Iran [22, 29].

Although temperature was shown as an important factor affecting the survival of Echinococus eggs [51], no relation between temperature and the occurrence of EC was found in current study. It could be explained by the higher effect of other mentioned factors and more important role of humidity in the survival of eggs in this mostly semi-arid region of Iran.

\section{Conclusions}

This reasonably sized retrospective study from Fars province has shown that the density of cattle and dogs and the urban setting were strongly implicated in CE transmission whilst humidity and farmlands were highly suggestive. Univariate models showed several important factors which were not significant in the multivariate analysis like proximity to NTRs, dog, camel and sheep density and slope but these factors have been reported as important by others.

A greater understanding of the human, dog, and intermediate host and climatic factors will help CE control programmes to better devise mitigations strategies. In particular, more research is needed on the relation between abattoir location and $\mathrm{CE}$ and the effect of the changing lifestyle of the nomadic populations. Researcph that integrates GIS, molecular based studies and human behavior would also inform policy makers.

\section{Abbreviations}

CE: Cystic Echinococcosis; GIS: Geographical Information Systems; DEM: Digital Elevation Model; MAT: Mean Annual Temperature; maximum MAT: Maximum Mean Annual Temperature; minimum MAT: Minimum Mean Annual Temperature; MAH: Mean Annual Humidity; MAR: Mean Annual Rainfall; MAE: Mean Annual Evaporation; TR: Nomads' Travel Routes; E. granulosus s. I: Echinococcus granulosus sensu lato

\section{Acknowledgments}

Our thanks are due to Hassan Khajehei for copy editing of the manuscript.

Authors' contributions

MAG and GP conceived and designed the study. FS, FZ and HA collected the data.

MAG analysed and interpreted the data. MAG, KN, WRT and ZK wrote the first draft of the manuscript. MAG, MK and WRT reviewed and edited the manuscript. All authors read and approved the final manuscript.

\section{Funding}

This study was supported by Yasuj University of Medical Sciences (Grant No.2/3049). The funding body had no role in designing the study, collecting data, analysing, interpreting, writing the manuscript, and deciding to publish the results.

\section{Availability of data and materials}

All data were retrieved from hospital records almost all from Namazi hospital, Shiraz the main referral hospital in southwest Iran. Retrieved data were and gathered in Professor Alborzi Clinical Microbiology Research Center in Namazi hospital in Shiraz.

The datasets generated and/or analysed during the current study are not publicly available due to some geographical details of cities/villages that may be used by unauthorized persons but are available from the corresponding author on reasonable request. 


\section{Ethics approval and consent to participate}

This study was apporved by the Ethics Committee of Yasuj University of Medical Sciences (IR.YUMS.REC.1395.189). Patients information was anonymized and strict confidentiality of patients data was retained during the entire study.

\section{Consent for publication}

Not applicable.

\section{Competing interests}

The authors declare that they have no competing interests.

\section{Author details}

${ }^{1}$ Cellular and Molecular Research Center, Yasuj University of Medical Sciences, Yasuj, Iran. ${ }^{2}$ Medical Parasitology and Mycology Department, Yasuj University of Medical Sciences, Yasuj, Iran. ${ }^{3}$ Student Research Committee, Yasuj University of Medical Sciences, Yasuj, Iran. ${ }^{4}$ Mahidol Oxford Tropical Medicine Research Unit, Bangkok, Thailand. ${ }^{5}$ Centre for Tropical Medicine and Global Health, Nuffield Department of Medicine, University of Oxford, Oxford, UK. ${ }^{6}$ Department of Parasitology and Mycology, School of Medicine, Zanjan University of Medical Sciences, Zanjan, Iran. ${ }^{7}$ Allergy Research Center, Shiraz University of Medical Sciences, Shiraz, Iran. ${ }^{8}$ Student Research Committee, Shiraz University of Medical Sciences, Shiraz, Iran. ${ }^{9}$ Professor Alborzi Clinical Microbiology Research Center, Department of Paediatrics, Nemazee Teaching Hospital, School of Medicine, Shiraz University of Medical Sciences, Shiraz, Iran.

Received: 29 April 2020 Accepted: 30 September 2020

Published online: 27 October 2020

\section{References}

1. Cucher MA, Macchiaroli N, Baldi G, Camicia F, Prada L, Maldonado L, et al. Cystic echinococcosis in South America: systematic review of species and genotypes of Echinococcus granulosus sensu lato in humans and natural domestic hosts. Tropical Med Int Health. 2016;21(2):166-75.

2. Gholami S, Tanzifi A, Sharif M, Daryani A, Rahimi MT, Mirshafiee S, et al. Demographic aspects of human hydatidosis in Iranian general population based on serology: a systematic review and meta-analysis. Vet world. 2018; 11(10):1385-96.

3. Chalechale A, Hashemnia M, Rezaei F, Sayadpour M. Echinococcus granulosus in humans associated with disease incidence in domestic animals in Kermanshah, west of Iran. J Parasit Dis. 2016;40(4):1322-9.

4. Moro P, Schantz PM. Echinococcosis: a review. Int J Infect Dis. 2009;13(2): $125-33$

5. Nakamura K, Ito A, Yara S, Haranaga S, Hibiya K, Hirayasu T, et al. A case of pulmonary and hepatic cystic echinococcosis of CE1 stage in a healthy Japanese female that was suspected to have been acquired during her stay in the United Kingdom. Am J Trop Med Hyg. 2011:85(3):456-9.

6. Pakala T, Molina M, Wu GY. Hepatic echinococcal cysts: a review. J Clin Transl Hepatol. 2016;4(1):39-46.

7. Manfredi M, Cerbo A, Zanzani S, Moriggia A, Fattori D, Siboni A, et al. Prevalence of echinococcosis in humans, livestock and dogs in northern Italy. Helminthologia. 2011;48(2):59-66.

8. Ilbeigi P, Mohebali M, Eshrat Beigom KI, Saber-Inasab M, Aryaeipour M, Bizhani N, et al. Seroepidemiology of human hydatidosis using AgB-ELISA test in Isfahan City and suburb areas, Isfahan province, Central Iran. Iran J Public Health. 2015;44(9):1219.

9. Rokni MB. Echinococcosis/hydatidosis in Iran. Iran J Parasitol. 2009;4(2):1-6.

10. Sadjjadi SM. Present situation of echinococcosis in the Middle East and Arabic North Africa. Parasitol Int. 2006;55(Suppl):S197-202.

11. Sharafi SM, Rostami-Nejad M, Moazeni M, Yousefi M, Saneie B, Hosseini-Safa A, et al. Echinococcus granulosus genotypes in Iran. Gastroenterol Hepatol Bed Bench. 2014;7(2):82.

12. Khademvatan S, Majidiani H, Foroutan M, Tappeh KH, Aryamand S, Khalkhali HR. Echinococcus granulosus genotypes in Iran: a systematic review. J Helminthol. 2019:93(2):131-8.

13. Shafiei R, Ghatee MA, Jafarzadeh F, Javanshir Z, Karamian M. Genotyping and phylogenetic analysis of unusually located hydatid cysts isolated from humans in north-East Iran. J Helminthol. 2019;94:e64.
14. Sharbatkhori M, Tanzifi A, Rostami S, Rostami M, Harandi MF. Echinococcus granulosus sensu lato genotypes in domestic livestock and humans in Golestan Province, Iran. Rev Inst Med Trop Sao Paulo. 2016;58:38.

15. Gorgani-Firouzjaee T, Kalantrai N, Ghaffari S, Alipour J, Siadati S. Genotype characterization of livestock and human cystic echinococcosis in Mazandaran province, Iran. J Helminthol. 2019;93(2):255-9.

16. Karamian M, Haghighi F, Hemmati M, Taylor WR, Salehabadi A, Ghatee MA Heterogenity of Echinococcus canadensis genotype 6- the main causative agent of cystic echinococcosis in Birjand, eastern Iran. Vet Parasitol. 2017; 245:78-85.

17. Possenti A, Manzano-Roman R, Sanchez-Ovejero C, Boufana B, La Torre G, Siles-Lucas M, et al. Potential risk factors associated with human cystic echinococcosis: systematic review and meta-analysis. PLoS Negl Trop Dis. 2016;10(11):e0005114.

18. Nur A, Abera B, Gunse T. The significance (socio-economic impact) and control of Echinococcosis/Hydatidosis: a review. EJBS. 2017;9(2):58-66.

19. Cromley EK. GIS and disease. Annu Rev Public Health. 2003;24:7-24.

20. Fakhar M, Karamian M, Ghatee MA, Taylor WR, Ghohe HP, Rasooli SA. Distribution pattern of anthroponotic cutaneous leishmaniasis caused by Leishmania tropica in Western Afghanistan during 2013-2014. Acta Trop. 2017;176:22-8.

21. Fletcher-Lartey SM, Caprarelli G. Application of GIS technology in public health: successes and challenges. Parasitology. 2016;143(4):401-15.

22. Ghatee MA, Haghdoost AA, Kooreshnia F, Kanannejad Z, Parisaie Z, Karamian M, et al. Role of environmental, climatic risk factors and livestock animals on the occurrence of cutaneous leishmaniasis in newly emerging focus in Iran. J Infect Public Health. 2018;11(3):425-33.

23. Hanafi-Bojd AA, Vatandoost H, Oshaghi MA, Charrahy Z, Haghdoost AA, Zamani $\mathrm{G}$, et al. Spatial analysis and mapping of malaria risk in an endemic area, south of Iran: a GIS based decision making for planning of control. Acta Trop. 2012;122(1):132-7.

24. Shafiei R, Teshnizi SH, Kalantar K, Gholami M, Mirzaee G, Mirzaee F. The seroprevalence of human cystic echinococcosis in Iran: a systematic review and meta-analysis study. J Parasitol Res. 2016;2016:1425147.

25. Sporone B. The status of nomadism as a cultural phenomenon in the Middle East. J Asian Afr Stud. 1972;7(1):122.

26. Chaâbane-Banaoues R, Oudni-M'rad M, M'rad S, Mezhoud H, Babba H. Environmental contamination by Echinococcus granulosus sensu lato eggs in relation to slaughterhouses in urban and rural areas in Tunisia. Korean J Parasitol. 2016;54(1):113-8.

27. Eslami A, Hosseini SH. Echinococcus granulosus infection of farm dogs of Iran. Parasitol Res. 1998;84(3):205-7.

28. Torgerson PR, Shaikenov BS, Rysmukhambetova AT, Ussenbayev AE, Abdybekova AM, Burtisurnov KK. Modelling the transmission dynamics of Echinococcus granulosus in dogs in rural Kazakhstan. Parasitology. 2003; 126(Pt 5):417-24.

29. Ghatee MA, Sharifi I, Haghdoost AA, Kanannejad Z, Taabody Z, Hatam G, et al. Spatial correlations of population and ecological factors with distribution of visceral leishmaniasis cases in southwestern Iran. J Vector Borne Dis. 2013;50(3):179-87.

30. Dalimi A, Motamedi GH, Hosseini M, Mohammadian B, Malaki H, Ghamari Z, et al. Echinococcosis/hydatidosis in western Iran. Vet Parasitol. 2002;105(2):161-71.

31. Mehrabani D, Oryan A, Sadjjadi SM. Prevalence of Echinococcus granulosus infection in stray dogs and herbivores in shiraz, Iran. Vet Parasitol. 1999; 86(3):217-20.

32. Ziaei H, Fakhar M, Armat S. Epidemiological aspects of cystic echinococcosis in slaughtered herbivores in sari abattoir, north of Iran. J Parasit Dis. 2011; 35(2):215-8.

33. Kebede N, Mekonnen H, Wossene A, Tilahun G. Hydatidosis of slaughtered cattle in Wolaita Sodo abattoir, southern Ethiopia. Trop Anim Health Prod. 2009;41(4):629-33.

34. Kouam MK, Meningue R, Fon DE. Parasitic causes of organ condemnation in cattle slaughtered in Fako abattoirs, south-west region of Cameroon, and estimate of financial losses. J Helminthol. 2019;93(3):367-71.

35. Regassa F, Molla A, Bekele J. Study on the prevalence of cystic hydatidosis and its economic significance in cattle slaughtered at Hawassa municipal abattoir, Ethiopia. Trop Anim Health Prod. 2010;42(5):977-84.

36. Thevenet PS, Jensen O, Drut R, Cerrone GE, Grenóvero MS, Alvarez HM, et al. Viability and infectiousness of eggs of Echinococcus granulosus aged under natural conditions of inferior arid climate. Vet Parasitol. 2005;133(1): $71-7$. 
37. Yang YR, Clements AC, Gray DJ, Atkinson JA, Williams GM, Barnes TS, et al. Impact of anthropogenic and natural environmental changes on Echinococcus transmission in Ningxia Hui autonomous region, the People's republic of China. Parasit Vectors. 2012;5:146.

38. Ebrahimipour M, Budke CM, Najjari M, Cassini R, Asmarian N. Bayesian spatial analysis of the surgical incidence rate of human cystic echinococcosis in north-eastern Iran. Acta Trop. 2016;163:80-6.

39. Mateus TL, Niza-Ribeiro J, Castro A, Vieira-Pinto M. Limited knowledge about hydatidosis among farmers in Northwest Portugal: a pressing need for a one health approach. Ecohealth. 2016;13(3):480-9.

40. Ahmadi NA. Hydatidosis in camels (Camelus dromedarius) and their potential role in the epidemiology of Echinococcus granulosus in Iran. J Helminthol. 2005;79(2):119-25.

41. Afshar A, Nazarian I, Baghban-Baseer B. A survey of the incidence of hydatid cyst in camels in South Iran. Br Vet J. 1971;127(11):544-6.

42. Mobedi I, Madadi H, Arfaa F. Camel, Camelus dromedarius, as intermediate host of Echinococcus granulosus in Iran. J Parasitol. 1970;56(6):1255.

43. Motakef M, Minou AA, Lari MM. An epidemiological approach to the study of Echinococcosis in north-east region of Iran (Khorassan). Pahlavi Med J. 1976;7(4):503-15.

44. Beiromvand M, Rafiei A, Mirzavand S, Rahdar M, Haddad FM. Screening of cystic echinococcosis and toxocariasis in rural inhabitants of Khuzestan Province, Southwest Iran. Trop Biomed. 2018;35(1):32-40.

45. Rafiei A, Hemadi A, Maraghi S, Kaikhaei B, Craig PS. Human cystic echinococcosis in nomads of south-West Islamic Republic of Iran. East Mediterr Health J. 2007;13(1):41-8.

46. Atkinson JA, Gray DJ, Clements AC, Barnes TS, McManus DP, Yang YR. Environmental changes impacting Echinococcus transmission: research to support predictive surveillance and control. Glob Chang Biol. 2013;19(3): 677-88.

47. Wang YH, Rogan MT, Vuitton DA, Wen H, Bartholomot B, Macpherson CN, et al. Cystic echinococcosis in semi-nomadic pastoral communities in northWest China. Trans R Soc Trop Med Hyg. 2001;95(2):153-8.

48. Laws GF. Physical factors influencing survival of taeniid eggs. Exp Parasitol. 1968;22(2):227-39.

49. Gemmell MA. Taeniidae: modification to the life span of the egg and the regulation of tapeworm populations. Exp Parasitol. 1977;41(2):314-28.

50. Guislain MH, Raoul F, Poulle ML, Giraudoux P. Fox faeces and vole distribution on a local range: ecological data in a parasitological perspective for Echinococcus multilocularis. Parasite. 2007;14(4):299-308.

51. Restrepo AM, Yang YR, McManus DP, Gray DJ, Giraudoux P, Barnes TS, et al. The landscape epidemiology of echinococcoses. Infect Dis Poverty. 2016; 5(1):13.

\section{Publisher's Note}

Springer Nature remains neutral with regard to jurisdictional claims in published maps and institutional affiliations.

\section{Ready to submit your research? Choose BMC and benefit from:}

- fast, convenient online submission

- thorough peer review by experienced researchers in your field

- rapid publication on acceptance

- support for research data, including large and complex data types

- gold Open Access which fosters wider collaboration and increased citations

- maximum visibility for your research: over $100 \mathrm{M}$ website views per year

At BMC, research is always in progress.

Learn more biomedcentral.com/submissions 